\title{
Delayed diagnosis of nasopharyngeal carcinoma in a patient with early signs of unilateral ear disorder
}

\author{
Marlinda Adham, Dadan Rohdiana, Ika D. Mayangsari, Zanil Musa \\ Department of Otorhinolaryngology, Faculty of Medicine, Universitas Indonesia, Cipto Mangunkusumo Hospital, Jakarta, Indonesia
}

\begin{abstract}
Abstrak
Karsinoma nasofaring (KNF) merupakan keganasan kepala leher paling sering di Indonesia. Keterlambatan diagnosis sering terjadi pada KNF karena gejala tidak spesifik seperti gangguan telinga unilateral. Kasus ini dilaporkan untuk mengingatkan pasien, keluarganya, dan dokter tentang gejala awal KNF dan faktor-faktor penyebab keterlambatan diagnosis. Laki-laki, 44 tahun, gejala awal gangguan telinga unilateral sudah konsultasi ke dokter (THT-KL, mata, syaraf, dan gigi) tetapi baru didiagnosis KNF stadium IVA (T4N1M0) 1 tahun kemudian. Gejala awal KNF tidak spesifik seperti keluhan telinga unilateral. Pasien, keluarganya dan dokter harus mecurigai KNF terhadap pasien dengan keluhan telinga unilateral yang tidak sembuh dengan pengobatan yang diberikan.
\end{abstract}

\begin{abstract}
Nasopharyngeal carcinoma (NPC) is the most frequent head and neck malignancy in Indonesia. Misdiagnosis of NPC is common because of unspecific symptoms as unilateral ear complaint. This case reminds doctors of the early symptoms of NPC and of other factors which lead to misdiagnosis and addresses also patients and their families. Reported is a 44 years old man with unilateral ear disorder that had been treated by otorhinolaryngologists, an ophthalmologist, a neurologist, and dentist first, but diagnosed with nasopharyngeal carcinoma stage IVA (T4N1M0) one year later. NPC has unspecific early symptoms such as unilateral ear disorder. Primarily doctors, but also patients and their families should be aware of unilateral ear complaint.
\end{abstract}

Keywords: misdiagnosis, nasopharyngeal carcinoma, unilateral ear disorders

pISSN: 0853-1773 • eISSN: 2252-8083 • http://dx.doi.org/10.13181/mji.v23i1.689 • Med J Indones. 2014;23:52-7 Correspondence author: Dadan Rohdiana, dadan_halsel@yahoo.com

Nasopharyngeal carcinoma (NPC) has a high incidence rate in Southern China, South East Asia, Japan, North Africa and the Middle East. ${ }^{1,2}$ The incidence rate of NPC in Southern China ranges from 15 to 50 per 100,000 inhabitants. ${ }^{3}$ The nasopharyngeal malignancy is the most common malignancy of head and neck in Indonesia, the fourth most common cancer after ovarium, breast and skin cancer. The incidence rate of NPC in Indonesia is 6.2 per 100,000 population or 12,000 new cases every year. ${ }^{4}$

Early detection of NPC is difficult, but early diagnosis is important to achieve optimum results of treatment. The difficulty of early NPC diagnosis is caused by unspecified early symptoms such as ear and nose complaints. Ear complaints in this malignancy have unilateral characteristic, such as Eustachian tube dysfunction, otitis media effusion, conductive hearing loss and ear pain..$^{5-7}$
NPC patients in early stage (T1, T2, N0-1 without metastasis) have a 5 years survival rate of $85 \%$, whereas in advanced stage (T3, T4 dan N2, N3 without metastasis) the 5 years survival rate is $65 \% .{ }^{5,8}$ The 10 years free disease rate in early stage is $67-71 \%$ and for advanced stage it is 29 - 54\%. Therefore, it is important to recognize factors related to the delay of symptoms and misdiagnosis to improve identifi and early management. ${ }^{9}$

\section{CASE REPORT}

We reported one case of a 44-year-old man, Sumatran ethnicity from Lampung Province with chief complaint about intermittent tinnitus in right ear since one year. The tinnitus disappeared in physical activity. Patient also complained about loss of hearing in the right ear, fullness in right ear, headache, and pain in the right retroorbital region. There was no history of otorrhea and head trauma. There was 
no complaint on the left ear. This patient did not complain about stuffed nose or bleeding from the nose. He presented to the first otorhinolaryngologist and was told that he did not have any disease and should consult to a dentist. He was given ear drops.

He consulted to a dentist and was told that there was a decay in left upper tooth. His tooth was extracted but the complaints did not decrease. Three months later, the patient complained of tinnitus and fullness in the right ear. He consulted to the second otorhinolaryngologist and was told that there was no disorder. The patient received ear drops and 10 times ear thermal therapy, but there was still no improvement.

Three months after he had presented to the second otorhinolaryngologist, the patient complained about double vision in the right eye. There was no blurred vision and no complaint of the nose. The patient presented again to the second otorhinolaryngologist and was consulted to a neurologist and an ophthalmologist. Patient was transferred to do computed tomography and no abnormality was found. He was only given analgetics until 4 months. The ophthalmologist stated that the eye complaint was only caused by tiredness in the eye and recommended vitamins to improve his vision.

In February 2012, four months after he consulted with the neurologist the patient went to the third

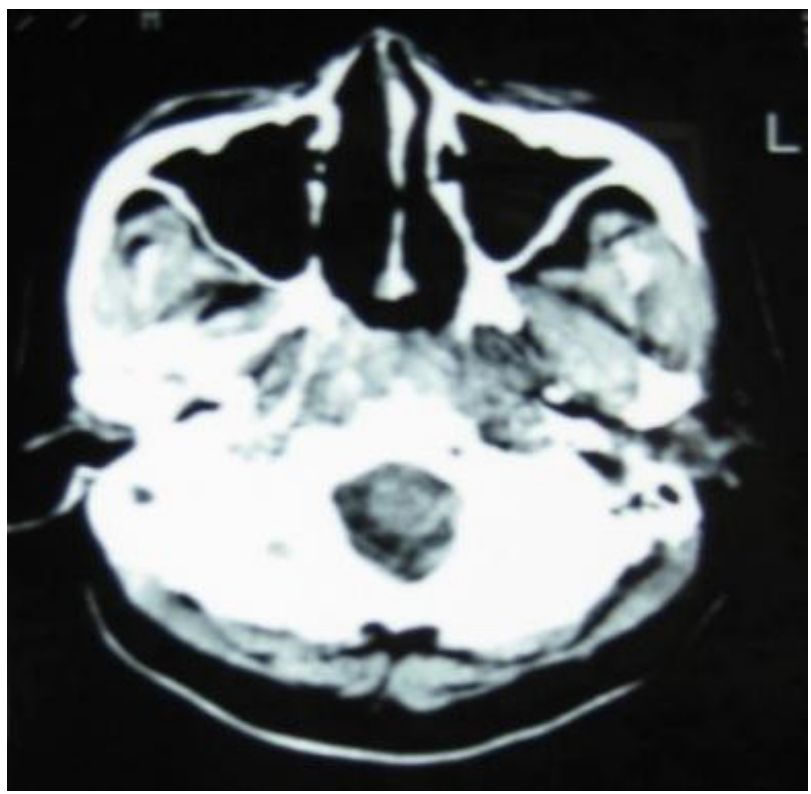

Figure 1. Computed tomography with normal result, while there is asymmetry of the right nasopharyngeal area otorhinolaryngologist with the same complaints and was told again that there was no disorder. The patient was suggested to go to another dentist for further evaluation. Then, he underwent panoramic radiography. The radiographic examination showed sclerotic finding around the radices of the upper right teeth number 4 through 8 with the possibility of chronic periodontitis. The upper left teeth number 7 and 8, right lower region number 6 and 7, and left lower region number 6 and 8 had already fallen out. There was no radical cyst or granuloma. The dentist extracted 4 teeth in the upper right region, but complaints did not improve.

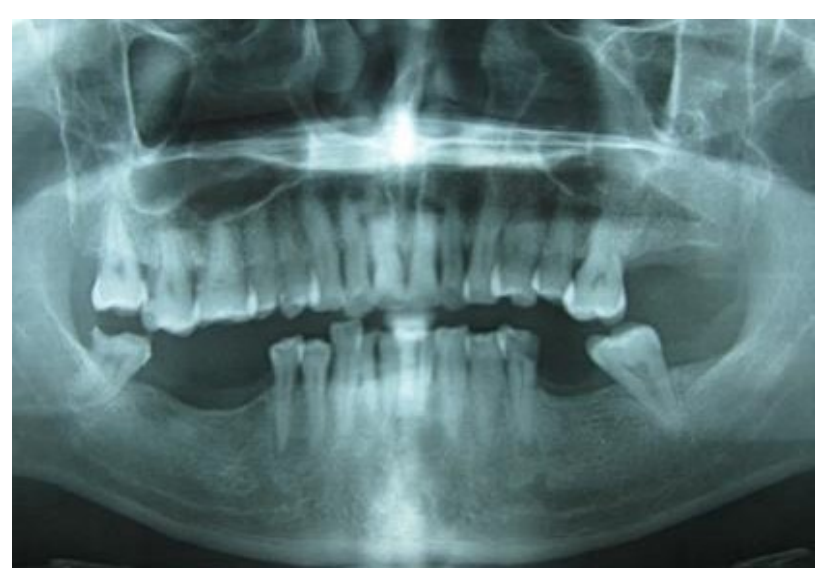

Figure 2. Panoramic examination showed chronic periodontitis of upper right teeth number 4 through 8

In April 2012, exactly one year after his fi complaints, the patient presented to the fourth otorhinolaryngologist with the same complaints and was subjected to audiologic examination with tune fork, audiometry, and timpanometry. From Weber examination there was lateralization to the right ear. From the audiometry result there was a mild conductive hearing loss with threshold of $35 \mathrm{~dB}$ at the right ear and $10 \mathrm{~dB}$ at the left ear. The tympanometry results were type B on the right ear and type $\mathrm{A}$ at the left ear.

The patient was diagnosed with right otitis media effusion and consulted to the fi otorhinolaryngologist for nasopharyngeal malignancy suspicion.

The fifth otorhinolaryngologist examined the right ear with result of wide ear canal, no secrete, no cerumen, intact tympanic membrane and decreased cone of light reflection. The left ear examination showed wide ear canal, no secrete, no cerumen, intact tympanic membrane and normal cone of light reflection. Examination in the right and left nasal cavities showed wide nasal cavity, eutrophy 
inferior turbinate, no deviation of septum and mass. From throat examination, the pharyngeal arch was symmetrical, uvula in the middle, tonsil T1/T1, and normal posterior pharyngeal wall. The examination in the right neck region revealed lymph node enlargement level II sized 1.5 x $1 \mathrm{~cm}^{2}$.

Nasoendoscopic examination resulted in mass with smooth surface on right nasopharyngeal roof which obliterates Rosenmuller fossa, torus tubarius, and narrowed Eustachian tube.

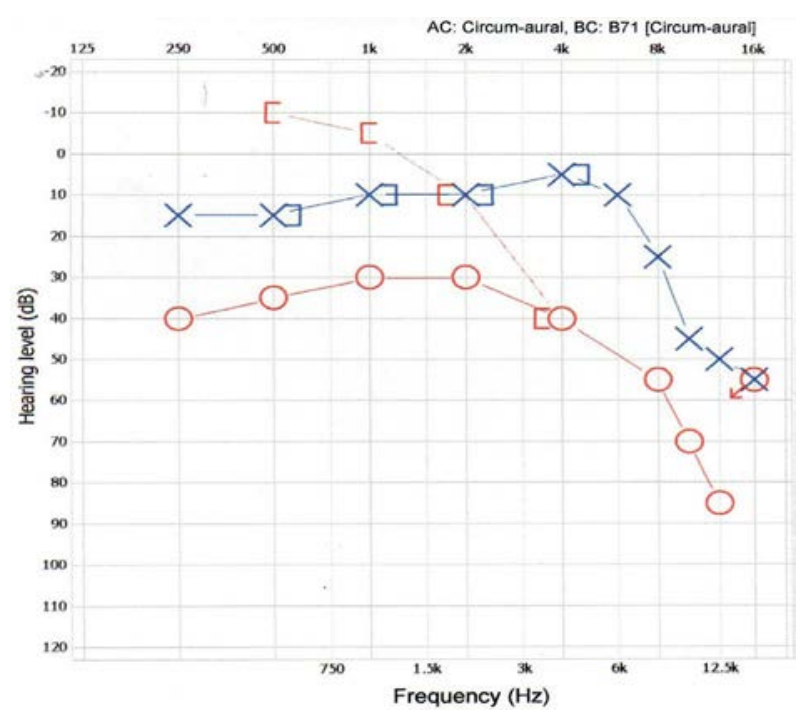

Figure 3. Audiometry examination of the right ear showed mild conductive hearing loss at threshold $35 \mathrm{~dB}$
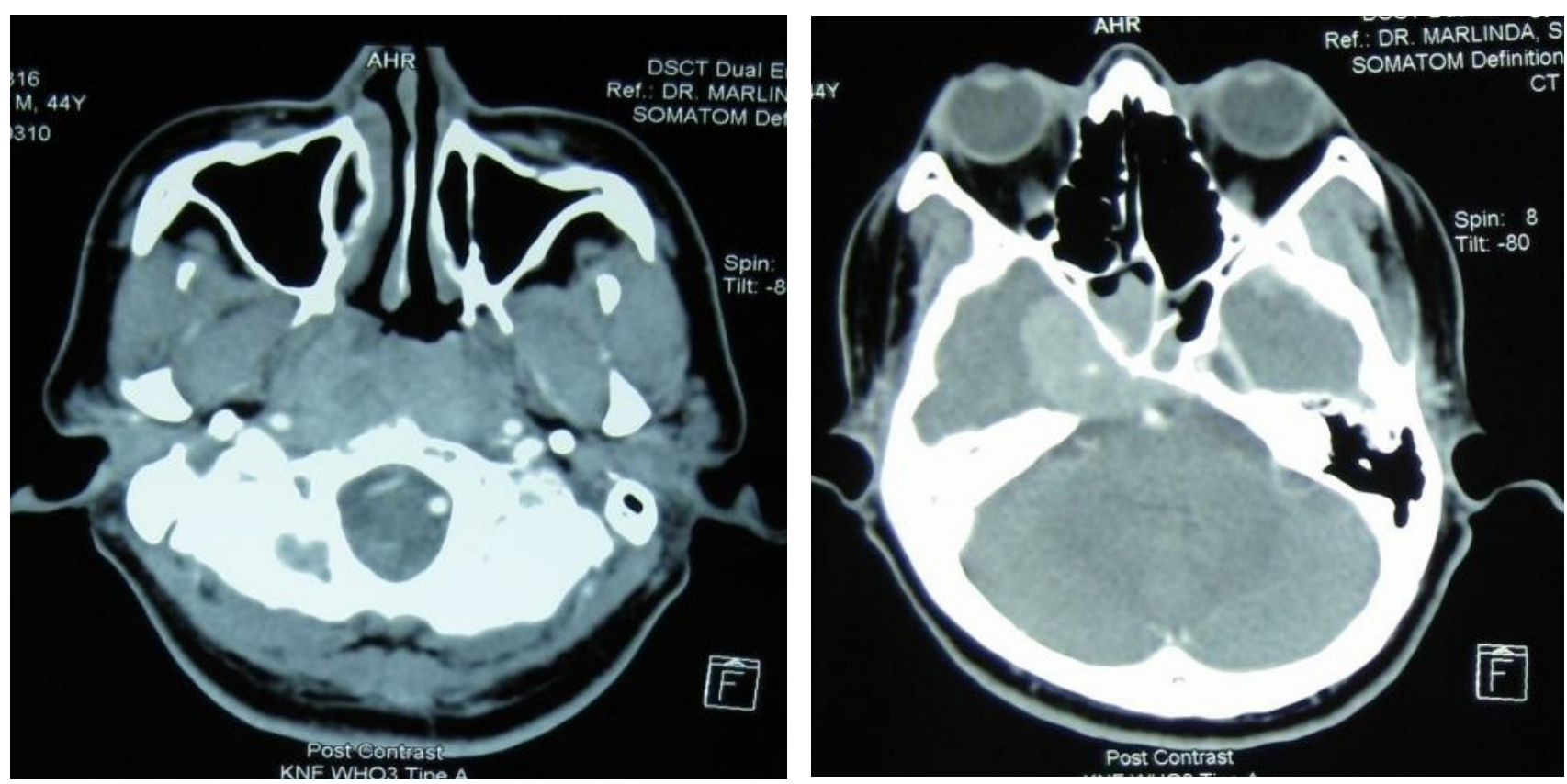

Figure 5. Computed tomography showed nasopharyngeal mass with extension to the surrounding structure infi the intracranium and right temporal lobe. Lymph nodes enlargement of left submandibular and colli bilateral with biggest size of $1.6 \mathrm{x} 0.9 \mathrm{~cm}$ including sinusitis maxilaris sinistris
Computed tomography re-examination showed nasopharyngeal mass with extension to the surrounding structure and infiltrate intracranially and also infiltrate to the right temporal lobe. There was lymph nodes enlargement in left submandibular region and colli bilateral region with biggest size of $1.6 \times 0.9 \mathrm{~cm}^{2}$ and left maxillary sinusitis.

The nasopharyngeal biopsy represented undifferentiated, keratinized nasopharyngeal carcinoma (WHO-3), type A (WF), moderate

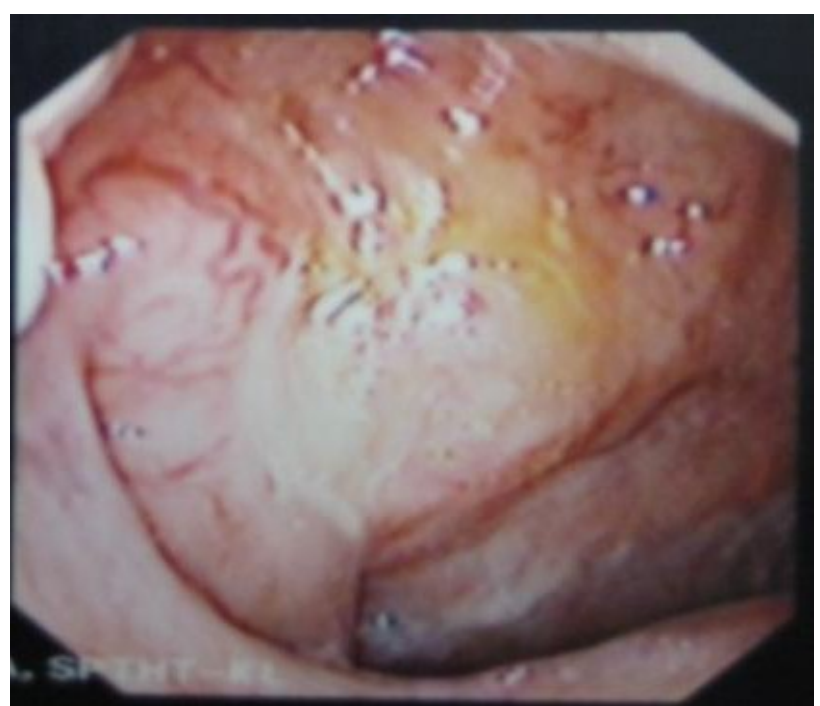

Figure 4. Nasoendoscopic examination showed mass with smooth surface on the right nasopharyngeal roof 
malignancy. Thorax x-ray, abdominal ultra sonography, and bone scan showed no further metastases.

The patient was also consulted to an ophtalmologist, a dentist, and neurologist. In accordance with consultation reports, the eye movement showed no abnormality in each direction, anterior and posterior segment showed no abnormality, funduscopy was within normal limit, impression of right and left eye was normal. The dentist found no focal infection in the oral cavity, so that the dental treatment was finished and the patient could be radiated. Neurologist consultation found that there were lesions at the right trigeminal nerve; first, second, and third branch (sensoric), diplopia (right abduscen nerve paresis), right facialis nerve paresis. Thus, the conclusions were multiple cranial palsy with suspect of infiltration into cranial base.

In conclusion, the patient had NPC WHO type 3 T4N1M0 (stage IV A) and treated with chemoradiation: 33 times radiation with 66 Gy and chemotherapy weekly with cisplatin $60 \mathrm{mg} / \mathrm{m}^{2}$. Eight weeks post-treatment, the result from clinical and radiologic examination showed complete response.

\section{DISCUSSION}

This report is about 44 year old male patient with unilateral ear disorder and late diagnosis of nasopharyngeal carcinoma. The ear disorder is the most common initial complaint of NPC, reaching $89 \%$ as reported by Abdullah, et al ${ }^{10}$ or $60 \%$ based on the report of Adham, et al. ${ }^{4}$

Ear disorder is not a specific for nasopharyngeal symptom even though it is a common complaint in early stage of NPC and therefore, diagnosis for NPC is often late. Ear disorder in NPC is usually unilateral, with tinnitus as a form of Eustachian tube disorder, otitis media effusion, conductive hearing loss, and otalgia. The ear symptom may be diagnosed as another common ear disease or to be caused by upper tract respiratory infection. This happens because "ear symptom” is not pathognomonic for NPC, especially in low rate incidence area. ${ }^{4,7,11}$

Our patient had no enlargement of cervical lymph nodes as further complaint and nasal symptom. The enlargement of cervical lymph nodes and nasal symptoms are the most common reasons that couse patients come to health care professionals. Muthanna and Alaryani ${ }^{12}$ reported that among 100 patients with
NPC, 60\% had enlarged cervical lymph nodes and $50 \%$ had nasal symptom, while Alabi, et al ${ }^{13}$ reported that $96.7 \%$ of 30 patients had enlarged cervical lymph nodes and $66.7 \%$ of them had nose bleeding.

The desire of patients to overcome their ear complaint is high. This can be seen from the high number of patients who visit an otorhinolaryngologist directly after suffering ear symptoms and in this case from the history of previous multiple visits to other specialists who did not manage to improve the patient's symptoms. The doctors did not consider ear symptoms as an early indication of NPC, but considered dental disorder as the cause. The medical history of double vision is a symptom of advanced NPC which caused paralysis of cranial nerve 3,4 , and 6 .

Some studies state that there are two factors as the cause of misdiagnosis of NPC, which are patient factors (patient delay) and health system factors (professional delay). Improper diagnosis, lack of suspicion of NPC by professional health practitioners and consideration of dental abnormalities play a very important role in late diagnosis. ${ }^{14-16}$

Delay in diagnosis may be up to 12 months counted from the firstconsultation to an otorhinolaryngologist. This is similar to the report by Prassad and Pua ${ }^{15}$ that health professionals diagnose NPC within 127 days on the average, which means, more than 4 months. Patients with nasal complaint as an early symptom will be diagnosed of NPC within 26 days, with intracranial symptoms within 51 days, with cervical lymph nodes enlargement in 3 months, and with ear symptoms in nearly 9 months. ${ }^{15}$

Patients' unilateral otitis media efusion may be caused by Eustachian tube dysfunction as the result of tumor depression. ${ }^{17}$ This symptom can be examined by otoscopy, audiometry, and tympanometry, while nasoendoscopy and nasopharyngeal biopsy can be used to diagnose NPC. This corresponds with the research by Glynn, et $\mathrm{al}^{18}$ who tried to correlate the incidence of serous otitis media with the incidence of NPC.

The otorhinolaryngologist, neurologist, and dentist as medical practitioners were not able to diagnose an early case of NPC. These practitioners were not aware of NPC as differential diagnosis leading to misdiagnosis. This may be due to the difficulty of nasopharyngeal examination and the fact that NPC has unspecific symptoms. ${ }^{9,19}$ 
Nasoendoscopic examination can show the involvement of mucosa and the tumor expansion to the nasal cavity or oropharynx,${ }^{20}$ while examination of biopsy samples from the nasopharynx will confi the diagnosis and determine the histopathologic type. ${ }^{11,18}$

The histologic feature of our patient was a type A undifferentiated non keratinizing carcinoma. WHO 1978 classifi this histologic feature into type $3,{ }^{19}$ while based on WHO 2005 classifi

this feature is included in type 2, which is a non keratinizing carcinoma with undifferentiated subtype. ${ }^{21}$ Undifferentiated carcinoma has a higher success rate for local tumor therapy but has a higher incidence of metastasis compared to well-differentiated type. ${ }^{2}$ Type $\mathrm{A}$ is related to prognosis as stated by Hsu, et $\mathrm{al}^{22}$ that type A is an intermediate malignancy with $30-40 \%$ survival rate. ${ }^{22}$

Staging of NPC in this patient is based on a complete physical examination, CT scan, chest xray, abdominal ultrasound, and bone scan. Based on these examinations, the staging of this patient is T4N1M0 according to AJCC/IUCC 2010. CT scan examination was demonstrated to evaluate the expansion of primary tumor and the presence of nodal enlargement, while chest x-ray, abdominal ultrasound, and bone scan were demonstrated to evaluate the presence of distant metastasis. ${ }^{11,19,23}$

This patient was given chemoradiation therapy according to NCCN 2011 and based on AJCC/UICC 2010, which stated that T1, N1-3, or T2-4, all N (stage II, III, IVa, IVb) NPC should be given concurrent chemoradiation. Adjuvant chemotherapy or induction chemotherapy can be added to the treatment protocol. ${ }^{23}$

This patient had had 85\% survival rate for 5 years and $67-71 \%$ for 10 years free of recurrency rate, if he was diagnosed earlier. Due to the delay of diagnosis, the patient was diagnosed at T4N1M0 (stage IVA), which has $65 \%$ of 5 years survival rate and $29-54 \%$ of 10 years free of recurrency rate. The delay of diagnosis in this patient decreased the quality of life, increased the fi burden, and also increased psychological problems for the patient and his family.

In conclusion, early diagnosis of NPC is essential for the prognosis. NPC has unspecific early symptoms, such as unilateral ear complaint. Therefore, medical practitioners must improve their diagnostic capabilities especially in differential diagnosis and to consider the possibility of NPC. Patients and their families should also be aware of these complaints in regions with high incidence of NPC.

\section{Conflict of interest}

The authors declare that this study is free of conflict of interest.

\section{REFERENCES}

1. Yoshizaki T, Ito M, Murono S, Wakisaka N, Kondo S, Endo K. Current understanding and management of nasopharyngeal carcinoma. Auris Nasus Larynx. 2012;39(2):137-44.

2. Tabuchi K, Nakayama M, Nishimura B, Hayashi K, Hara A. Early detection of nasopharyngeal carcinoma. International Journal of Otolaryngology. 2011;2011:1-6.

3. Chan AT, Teo PM, Johnson PJ. Nasopharyngeal carcinoma. Ann Oncol. 2002;13(7):1007-15.

4. Adham M, Kurniawan AN, Muhtadi AI, Roezin A, Hermani B, Gondhowiardjo S, et al. Nasopharyngeal carcinoma in Indonesia: epidemiology, incidence, signs, and symptoms at presentation. Chin J Cancer. 2012;31(4):185-96.

5. Wildeman MA, Fles R, Adham M, Mayangsari ID, Luirink I, Sandberg M, et al. Short-term effect of different teaching methods on nasopharyngeal carcinoma for general practitioners in Jakarta, Indonesia. Plos ONE. 2012;7(3):1-7.

6. Low WKC, Rangabashyam M. Ear-related issues in patients with nasopharyngeal carcinoma. In: Chen SS, editor. Carcinogenesis, diagnosis, and molecular targeted treatment for nasopharyngeal carcinoma. Croatia: InTech; 2012. p. 155-78.

7. Daniel A, Fasunla AJ. Nasopharyngeal cancer mimicking otitic barotrauma in a resource-challenged center: a case report. J Med Case Rep. 2011;5:532.

8. Lee AW, Poon YF, Foo W, Law SC, Cheung FK, Chan DK, et al. Retrospective analysis of 5037 patients with nasopharyngeal carcinoma treated during 1976-1985: overall survival and patterns of failure. Int J Radiat Oncol Biol Phys. 1992;23(2):261-70.

9. Sing TT, Subramaniam SK. Factors of late presentation and diagnosis of nasopharyngeal carcinoma in Sarawak Malaysia. The Internet Journal of Head and Neck Surgery. 2007;1(1):1.

10. Abdullah NE, Adam AAM, Khalifa EH, Hassan LAM, Ibrahim ME, Hamad KM, et al. Nasopharyngeal cancer in Sudan: epidemiology, clinical and histological characteristics. Clin Med Insights Ear Nose Throat. 2011;4:5-11.

11. Abdullah B, Alias A, Hassan S. Challenges in the management of nasopharyngeal carcinoma: a review. Malays J Med Sci. 2009;16(4):50-4.

12. Muthanna AO, Alaryani A. Clinical presentation of nasopharyngeal cancer in Yemen. Egypt J Biomed Sci. 2007;23(1):237-43.

13. Alabi BS, Badmos KB, Afolabi OA, Buhari MO, SegunBusari S. Clinico-pathological pattern of nasopharyngeal carcinoma in Ilorin, Nigeria. Niger $\mathrm{J}$ Clin Pract. 2010;13(4):445-8.

14. Al-Rajhi N, El-Sebaie M, Khafaga Y, AlZahrani A, Mohamed G, Al-Amro A. Nasopharyngeal carcinoma in 
Saudi Arabia: clinical presentation and diagnostic delay. East Mediterr Health J. 2009;15(5):1301-7.

15. Prasad U, Pua KC. Nasopharyngeal carcinoma: a delay in diagnosis. Med J Malaysia. 2000;55(2):230-5.

16. Mackie AM, Epstein JB, Wu JS, Stevenson-Moore P. Nasopharyngeal carcinoma: the role of the dentist in assessment, early diagnosis and care before and after cancer therapy. Oral Oncol. 2000;36(5):397-403.

17. Smerq, J. Sharma, M. The Risk Factor: Nasopharyngeal Carcinoma. IJPCR. 2011;3(3):48-51.

18. Glynn F, Keogh IJ, Ali TA, Timon CI, Donnelly M. Routine nasopharyngeal biopsy in adults presenting with isolated serous otitis media: is it justified? J Laryngol Otol. 2006;120(6):439-41.
19. Brennan B. Nasopharyngeal carcinoma. Orphanet Journal of Rare Diseases. 2006;1:23.

20. Wei WI, Sham JST. Nasopharyngeal carcinoma. Lancet. 2005;365(9476):2041-54.

21. IARC. Pathology and genetics of head and neck tumours. World Health Organization Classifi of Tumours. Lyon. 2005.

22. Hsu HC, Chen CL, Hsu MM, Lynn TC, Tu SM, Huang SC. Pathology of nasopharyngeal carcinoma. Proposal of a new histologic classification correlated with prognosis. Cancer. 1987;59(5):945-51.

23. National Comprehensive Cancer Network. NCCN clinical practice guideline in oncology (NCCN guidelines) head and neck cancer. Version 2. 2011. 